DEUTSCHE AKADEMIE DER WISSENSCHAFTEN ZU BERLIN VORTRÄGE UND SCHRIFTEN

HEFT 40

\author{
Hermann Grapow
}

\title{
DIE BEGRÜNDUNG DER
}

\section{ORIENTALISCHEN KOMMISSION}

\section{VON 1912}

\author{
Aus der Geschichte der Akademie \\ in den letzten funfzig Jahren
}

1950

AKADEMIE-VERLAG BERLIN 
Erschienen im Akademie-Verlag GmbH., Berlin NW 7, Schiffbauerdamm I9

Lizenz Nr. $156 \cdot 100 / 45 / 50$

Gedruckt in der Buchdruckerei Oswald Schmidt GmbH., Leipzig M ri8

Bestell- und Verlagsnummer 2003/40

Preis DM 2,25 